\title{
TEMA 8-2014: Enfermedad Celiaca y Síndrome de Down
}

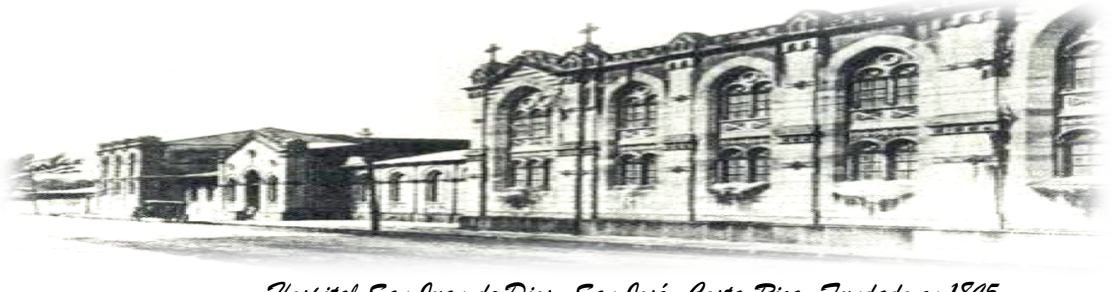

Hospital San quan de Dias. San Gasé. Costa Rica. Fundada en 1845

Recibido: 22/02/2014

Aceptado: $\quad 26 / 03 / 2014$

\author{
Adrián Castro Madrigal ${ }^{1}$ \\ Alejandra Acosta Gualandri ${ }^{2}$
}

\begin{abstract}
${ }^{1}$ Médico General. Universidad de Costa Rica. Correo electrónico adrian.castro10@gmail.com
${ }^{2}$ Médica Especialista en Pediatría. Servicio de Genética Médica y Metabolismo. Hospital Nacional de Niños.
\end{abstract}

\section{RESUMEN}

El síndrome de Down es la cromosomopatía más frecuente en el mundo occidental. Se encuentra asociada a alteraciones inmunológicas, entre ellas la enfermedad celíaca, con una prevalencia 10 veces más alta que en la población general. $\mathrm{La}$ enfermedad celíaca es una de las condiciones crónicas más comunes y corresponde a un desorden sistémico causado por una respuesta inmunológica al gluten. Dicha patología posee una clínica donde predominan los síntomas gastrointestinales como diarrea, constipación y distensión abdominal; que en caso de presentarse en niños con síndrome de Down debe exhortar a descartar enfermedad celíaca. El actual abordaje diagnóstico recomienda una prueba serológica del anticuerpo antitransglutaminasa tipo IgA y confirmación por medio de biopsia intestinal. El tratamiento consiste en una dieta libre de gluten.

\section{PALABRAS CLAVE}

Enfermedad celíaca. Síndrome de Down. Gluten. Antitransglutaminasa

\begin{abstract}
Down syndrome is the most frequent chromosomic anomaly in the western world and has been related to certain immune disorders such as celiac disease, which is 10 times more common in people with Down syndrome than in the general population. Celiac disease is one of the most common chronic conditions, being a systemic disorder caused by an immunologic response to gluten. The clinical manifestations are mainly gastrointestinal symptoms such as diarrhea, constipation, bloating, that if present in children with Down syndrome, should make the physician rule out celiac disease. The current diagnostic approach recommends a transglutaminase antibody IgA, followed by a confirmatory intestinal biopsy. Treatment in all cases is a gluten free diet.
\end{abstract}

\section{KEY WORDS}

Celiac disease. Down syndrome Gluten Antitransglutaminase. 


\section{INTRODUCCIÓN}

La enfermedad Celíaca (EC) es una de las condiciones crónicas más comunes identificada alrededor del mundo, excepto en el África subsahariana y en el este de Asia. Por su espectro clínico, serológico, genético e histopatológico tan amplio, la definición actual es la de un desorden sistémico, causado por una respuesta inmunológica al gluten y a las prolaminas relacionadas, en individuos genéticamente susceptibles y caracterizado por una combinación variable de manifestaciones glutendependientes, anticuerpos específicos, enteropatías y haplotipos HLA-DQ2 o HLADQ8. ${ }^{(1)}$

El síndrome de Down es la anomalía cromosómica más frecuente en el mundo occidental, con una incidencia en los Estados Unidos de 1 en cada 691 nacimientos vivos. Un importante porcentaje de los individuos con trisomia 21, presenta alteraciones en su sistema inmunológico, que abarca desde ciertas deficiencias inmunes específicas hasta problemas de índole autoinmune como hipotiroidismo, hipertiroidismo, diabetes tipo 1 y la enfermedad celíaca. $^{(2)}$

\section{DISCUSIÓN}

\section{Prevalencia}

La prevalencia de la enfermedad celíaca en la población general es del $1 \%$, aunque se ha sugerido que va en incremento en países desarrollados. Se ha reportado un claro aumento de la prevalencia de la enfermedad dentro de los individuos con síndrome de Down, con cifras tan elevadas como el $15 \%{ }^{(3,4)}$

\section{Fisiopatología}

La enfermedad celíaca es considerada un desorden autoinmune con componentes tanto ambientales como genéticos. El principal desencadenante ambiental lo constituye la exposición al gluten, la fracción proteica constituyente del trigo, la cebada y el centeno. Estas proteínas, ricas en prolina y glutamina no son digeridas correctamente en el tracto gastrointestinal y los residuos digestivos resultantes inician una respuesta innata y adaptativa en aquellos individuos genéticamente predispuestos. ${ }^{(1)}$ Existe una correlación del 20\% en parientes de primer grado afectados por la enfermedad, con una concordancia de 75 a $80 \%$ en gemelos monocigóticos y $10 \%$ en gemelos dicigóticos. ${ }^{(5)}$

Dentro de dicha respuesta adaptativa, la correlación que existe con los antígenos humanos leucocitarios (HLA) DQ2 y DQ8 ha cobrado tanta relevancia en los últimos años que los mismos juegan un papel importante en un eventual tamizaje de la enfermedad celíaca. ${ }^{(1)}$ Aunque el HLA-DQ2 y el HLA-DQ8 son necesarios para el desarrollo de la enfermedad, no son suficientes para desencadenarla, reflejando así la implicación de otros factores genéticos y ambientales en la fisiopatología de la enfermedad celíaca. ${ }^{(5)}$

Más del 95\% de los individuos con enfermedad celíaca expresan HLA-DQ2 mientras que el resto expresará HLA-DQ8. No obstante, 30-40\% de la población general expresa HLA-DQ2 por lo que solo su presencia no condiciona el desarrollo de la enfermedad y se presume que genes no relacionados con el antígeno de histocompatibilidad deben estar involucrados. ${ }^{(1)}$

La exposición al gluten es claramente el factor ambiental más relevante en el desarrollo de la enfermedad. Ciertos estudios epidemiológicos han sugerido que una introducción temprana o tardía del gluten a los niños, el parto por cesárea, infecciones en la infancia principalmente rotavirus y la ausencia de lactancia materna son factores de riesgo importantes en el desarrollo de la enfermedad celíaca. ${ }^{(5)}$

Los microorganismos intestinales y su papel como participantes en la enfermedad celíaca han surgido como otro factor importante en los últimos años. Los estudios del microbioma intestinal se encuentran todavía en etapas tempranas, con resultados conflictivos, probablemente debido a los abordajes experimentales tan distintos en muestras fecales o de biopsias en poblaciones de pacientes de diversos países. ${ }^{(5)}$

Aunque los eventos ambientales y genéticos, son requisitos para el desarrollo de la enfermedad celíaca, estos no son suficientes para explicar la inflamación presente en el intestino delgado. Otro aspecto esencial en la fisiopatología de esta condición es la disregulación inmune a nivel 
tanto del sistema innato como adaptativo. Distintas alteraciones a nivel de la inmunidad mediada por células $\mathrm{T}$ pertenecientes al sistema adaptativo y en linfocitos intraepiteliales del sistema innato han sido propuestos como explicación ha dicho fenómeno. ${ }^{(5)}$

\section{Clínica}

Las personas con síndrome de Down presentan los mismos síntomas que cualquier otro tipo de paciente. Los síntomas clásicos se observan con mayor frecuencia entre los niños de menores edades, refiriendo diarrea, distensión abdominal y falla para progresar. Estos pacientes tan jóvenes tienen una mayor probabilidad de presentarse con la diarrea y malabsorción características de la enfermedad, mientras que los adolescentes y niños mayores aquejan síntomas gastrointestinales más atípicos, como vómitos, constipación y dolor. ${ }^{(6)}$

En los adultos por su parte, menos del 50\% se presentan con diarrea, asociando otros problemas como anemia, osteoporosis y hallazgos incidentales como la atrofia de vellosidades intestinales durante una endoscopía, realizada por otras indicaciones. Otros síntomas asociados son dermatitis herpetiforme, síndrome de intestino irritable, fatiga crónica, entre otros. ${ }^{(6)}$

Al momento del diagnóstico de EC entre el 44 y $69 \%$ de los niños con SD presentan alguna manifestación de tipo abdominal y entre un $11 \mathrm{y}$ $39 \%$ presentan falla para progresar o anemia. Mientras que un $17 \%$ de los casos diagnosticados con EC se encuentran totalmente asintomáticos. La relación de personas sintomáticas y asintomáticas en la población general es de 1:8, mientras que en el $\mathrm{SD}$, esta relación se invierte a $4: 1^{(4)}$

\section{Tamizaje y Diagnóstico}

La EC presenta una frecuencia de 4 a $13 \%$ en individuos con SD. Sin embargo, aún es controversial la dicotomía para realizar estudios presintomáticos a los 2 años de edad o si en cambio se debe esperar hasta la presencia de manifestaciones clínicas. ${ }^{(7,8)}$ Las guías de supervisión en la salud de los niños con Síndrome de Down, de la Academia Americana de Pediatría, publicadas en el 2011 alertan a los médicos a tomar muy en serio en niños con síndrome de Down los síntomas de diarrea, constipación, crecimiento desacelerado, falla para progresar inexplicada, anemia, dolor o distensión abdominal y alteraciones del comportamiento. Todos estos síntomas en un niño con síndrome de Down pueden reflejar la presencia de la enfermedad celíaca y por tanto es recomendable realizar el tamizaje respectivo. ${ }^{(6,11)}$

La EC se caracteriza por anticuerpos creados contra la gliadina, un componente del gluten y componentes del tejido conectivo: la transglutaminasa tisular y los anticuerpos antiendomisio. Los anticuerpos antigliadina no están actualmente recomendados por su menor especificidad y sensibilidad frente a otras pruebas sanguíneas. Es importante destacar que hasta el $10 \%$ de las personas con enfermedad celíaca son seronegativas. ${ }^{(10)}$

La obtención de transglutaminasa tisular tipo IgA, (TTG IgA por sus siglas en inglés) en casos con alta sospecha clínica de enfermedad celíaca, es actualmente la prueba recomendada. Posee una sensibilidad y una especificidad del $98 \%$. Los falsos positivos son muy inusuales con sustratos humanos y los falsos negativos pueden detectarse realizando una cuantificación de $\operatorname{IgA}$ total simultánea, para así descartar deficiencia selectiva de IgA. Otras pruebas serológicas como el anticuerpo antiendomisio ha perdido utilidad y se toma en cuenta en aquellos casos en los cuales el resultado del anticuerpo antiglutaminasa es equívoco. ${ }^{(10)}$

Las pruebas genotípicas para determinar la presencia del HLA-DQ2 o HLA-DQ8 no están indicadas como primera línea en el diagnóstico de enfermedad celíaca, porque realmente no han demostrado un mejor resultado como prueba confirmatoria frente a las pruebas serológicas. ${ }^{(10)}$

La biopsia intestinal a nivel de duodeno es hoy en día el estándar de oro para el diagnóstico de la $\mathrm{EC}$, inclusive en pacientes con síndrome de Down. Está indicada como confirmación en aquellos pacientes con pruebas serológicas positivas o pacientes seronegativos con alta sospecha clínica de enfermedad celíaca y/o con pruebas genéticas positivas. Deben tomarse entre 4 y 6 biopsias del bulbo y la segunda porción de duodeno. A la endoscopía podría verse una pérdida de los pliegues, un patrón en mosaico y fisuras en la mucosa. Un tracto intestinal de apariencia normal no exenta la presencia de 
enfermedad celíaca, por lo que debe confirmarse con la biopsia. ${ }^{(10,11)}$

A nivel histológico, es esperable encontrar linfocitos intraepiteliales, hiperplasia de las criptas y atrofia de las vellosidades. ${ }^{(11)}$

\section{Tratamiento}

La piedra angular del tratamiento en pacientes con síndrome de Down y enfermedad celíaca es la adherencia de por vida a una dieta libre de gluten. Por definición, los alimentos libres de gluten deben contener menos de $20 \mathrm{mg} / \mathrm{kg}$ de gluten. Diferentes productos como pan, cereal, pastas, cerveza, sopas, salsas, aderezos, algunas pastas de dientes, entre otros, deben ser eliminados de la dieta y del consumo corriente de los pacientes con enfermedad celíaca. Es muy importante la educación sobre las etiquetas nutricionales de los distintos productos, con el fin de evitar aquellos que contienen gluten. ${ }^{(12)}$

Alrededor del 70\% de los pacientes responden prontamente al tratamiento, mostrando mejoría sintomática en semanas o días. Las principales razones de falla al tratamiento son la poca adherencia a la dieta libre de gluten o la ingestión inadvertida de gluten. ${ }^{(12)}$

Algunas permanecen asintomáticas con bajas ingestas de gluten. No obstante, debido a un mayor riesgo de linfoma intestinal, deficiencias nutricionales y osteoporosis, es recomendable aplicar una restricción total de gluten en pacientes con enfermedad celíaca. ${ }^{(4,12)}$

\section{CONCLUSIONES Y RECOMENDACIONES}

La enfermedad celíaca es uno de los padecimientos crónicos más frecuentes en el mundo occidental y es diez veces más común en los pacientes con síndrome de Down que en la población general.

Es importante tener en cuenta que estos individuos deben ser tamizados en caso de presentar los síntomas gastrointestinales típicos de la enfermedad, siendo la TTG IgA la prueba serológica de elección en la actualidad y confirmar el diagnóstico por medio de una biopsia duodenal.
El tratamiento más eficaz es la dieta libre de gluten, la que debe ser implementada de forma absoluta para así evitar un mayor riesgo de complicaciones que los pacientes con síndrome de Down podrían asociar con el tiempo.

\section{REFERENCIAS BIBLIOGRÁFICAS}

1. Denham J Hill Ivor. Celiac Disease and Autoimmunity: Review and Controversies. Current Allergy and Asthma Reports. 2013;13:347-353

2. Davidson M. Primary Care for children and adolescents with Down syndrome. Pediatr Clin N Am. 2008;55:10991111.

3. Dubé C Rostom A Sy R et al. The prevalence of celiac disease in average-risk and at-risk western European populations: a systematic review. Gastroenterology. 2005;128:S57-S67.

4. Swingoski N Kuhlenschmidt H Bull M Corkins M Downs S. Screening for Celiac Disease in Asymptomatic Children with Down Syndrome: Costeffectiveness of Preventing Lymphoma. Pediatrics. 2006;118:594-602.

5. Kupfer S Jabri B. Pathophysiology of Celiac Disease. Gastrointest Endoscopy Clin. 2012;22:639-660.

6. Bull M Committee on Genetics. Clinical Report-Health Supervision for Children with Down Syndrome. Pediatrics. 2011;128:393-406.

7. Roizen NJ Patterson D. Down Syndrome. Lancet. 2003;361:1281-1289

8. Carnicer J Farré C Varea V Vilar P Moreno J Artigas J. Prevalence of coeliac disease in Downs syndrome. Eur J Gastroenterol Hepatol. 2001;13:263267.

9. Reilly N Fasano A Green P. Presentation of Celiac Disease. Gastrointest Endoscopy Clin. 2012;22:613-621.

10. Lebwohl B Rubio-Tapia A Assiri A Newland C Guandalini S. Diagnosis of Celiac Disease. Gastrointest Endoscopy Clin. 2012;22:661-677.

11. Tennyson C Semrad C. Small Bowel Imaging in Celiac Disease. Gastrointest Endoscopy Clin. 2012;22:735-746.

12. Nasr I Leffler D Ciclitira P. Management of Celiac Disease. Gastrointest Endoscopy Clin. 2012;22:695-704. 
DECLARACIÓN DE CONFLICTO DE INTERESES

Los autores declaran que no existen conflictos de intereses.

\section{AGRADECIMIENTOS}

A todo el equipo de la Clínica de síndrome de Down del Hospital General de Massachusetts por la introducción al tema. 